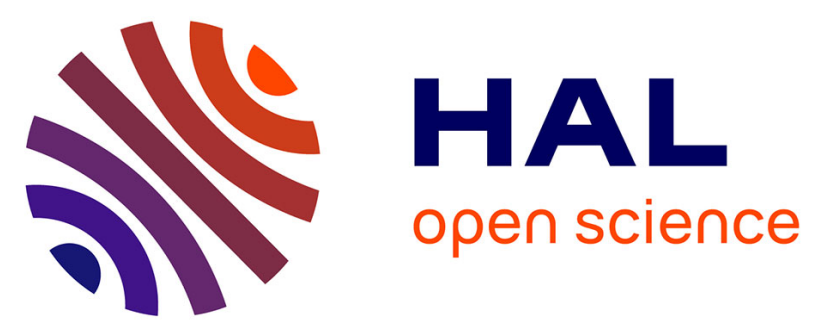

\title{
Localization of the GABAergic and non-GABAergic neurons projecting to the sublaterodorsal nucleus and potentially gating paradoxical sleep onset.
}

\author{
Romuald Boissard, Patrice Fort, Damien Gervasoni, Bruno Barbagli, \\ Pierre-Hervé Luppi
}

\section{To cite this version:}

Romuald Boissard, Patrice Fort, Damien Gervasoni, Bruno Barbagli, Pierre-Hervé Luppi. Localization of the GABAergic and non-GABAergic neurons projecting to the sublaterodorsal nucleus and potentially gating paradoxical sleep onset.. European Journal of Neuroscience, 2003, 18 (6), pp.1627-39. hal-00113897

\section{HAL Id: hal-00113897 \\ https://hal.science/hal-00113897}

Submitted on 30 Nov 2006

HAL is a multi-disciplinary open access archive for the deposit and dissemination of scientific research documents, whether they are published or not. The documents may come from teaching and research institutions in France or abroad, or from public or private research centers.
L'archive ouverte pluridisciplinaire HAL, est destinée au dépôt et à la diffusion de documents scientifiques de niveau recherche, publiés ou non, émanant des établissements d'enseignement et de recherche français ou étrangers, des laboratoires publics ou privés. 


\section{Localization of the GABAergic and non-GABAergic neurones projecting to the}

\section{sublaterodorsal nucleus and potentially gating paradoxical sleep onset}

Romuald Boissard, Patrice Fort, Damien Gervasoni, Bruno Barbagli and Pierre-Hervé Luppił

Address : $\quad$ CNRS FRE2469, Institut Fédératif des Neurosciences de Lyon (IFR 19), Université Claude Bernard Lyon I, 7, Rue Guillaume Paradin, 69372 LYON Cedex 08, FRANCE

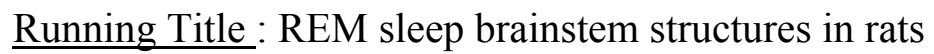

Number of text pages :

Number of Figures:

Number of tables:

Numbers of words in the Abstract : 250

Introduction : 820

Manuscript :

$\$$ Corresponding author

CNRS FRE2469, Faculté de Médecine Laennec,

7, Rue Guillaume Paradin, 69372 LYON cedex 08, FRANCE

Tel number $\quad(+33) 478771003$

Fax number $\quad(+33) 478771022$

E-mail luppi@sommeil.univ-lyon1.fr

Key Words: REM sleep, glycine, GABA, subcoeruleus, C-Fos, peri-LC 


\section{Abstract}

We recently determined in rats that iontophoretic application of bicuculline or gabazine (two GABAa antagonists) and kainic acid (a glutamate agonist) in the sublaterodorsal nucleus (SLD) induces with a very short latency a paradoxical sleep-like state. From these results, we proposed that GABAergic and glutamatergic inputs to the SLD PS-executive neurones gate the onset of paradoxical sleep (PS) (Boissard et al., 2002). We therefore decided to determine the origin of the GABAergic and non-GABAergic inputs to the SLD combining injection of a retrograde tracer (cholera toxin B subunit, $\mathrm{CTb}$ ) with glutamate decarboxylase (GAD) immunohistochemistry. The presence of GAD-immunoreactive neurones in the SLD was first confirmed. Then, following CTb injections centered on the SLD combined with GAD immunohistochemistry, GAD and CTb double-labelled cells were mainly observed in the mesencephalic and pontine reticular nuclei and to a lesser extent the parvicellular reticular nucleus. A large number of GAD-negative retrogradely labelled cells was also seen in theses structure as well as in the primary motor area of the frontal cortex, the central nucleus of the amygdala, the ventral and lateral bed nucleus of the stria terminalis, the lateral hypothalamic area, the lateral and ventrolateral periaqueductal gray and the lateral paragigantocellular reticular nucleus. From these results, we propose that the activation of PS-executive neurones from the SLD is due to the removal of a tonic inhibition from GABAergic neurones localized in the SLD and the mesencephalic and pontine reticular nuclei. Strong nonGABAergic inputs to the SLD could be excitatory and responsible for the tonic glutamatergic input to the PS-on neurons found in our previous paper. They could also terminate on SLD GABAergic interneurons and be indirectly responsible for the inhibition of the PS-on neurons during waking and slow wave sleep. 


\section{Introduction}

We recently showed in rats that iontophoretic application of bicuculline or gabazine (two GABAa antagonists) and kainic acid (a glutamate agonist) specifically in the sublaterodorsal nucleus (SLD) induces with a very short latency a paradoxical sleep-like (PS-like) state characterized by muscle atonia, EEG activation and theta activity (Boissard et al., 2002). The ejection of carbachol in the same area failed to induce the same state. From these results, we hypothesized that PS-executive neurones (PS-on neurones) localized in the SLD are tonically inhibited during waking (W) and slow wave sleep (SWS) by GABAergic neurones. The presence in the SLD of GABAergic neurones (Ford et al., 1995) indicated that PS-on neurones could be inhibited by GABAergic interneurones. However, the GABAergic inhibition could also arise from distant GABAergic neurones since long GABAergic projections to brainstem nuclei have been described (Ford et al., 1995; Gervasoni et al., 2000). Moreover, the location of the non-GABAergic neurones projecting to the SLD in position to control PS-executive neurones also remained to be identified. Indeed, in previous retrograde tracing studies on the afferents to the pontine PS-executive region, the sites of injection obtained were localized in the pontine reticular nucleus (Shammah-Lagnado et al., 1987; Leichnetz et al., 1989; Quattrochi et al., 1989; Lai et al., 1993; Semba, 1993) ventral to the PS-executive region as reported by Boissard et al (2002) and Sakai et al. (1981) which corresponds to the rat SLD and the cat nucleus peri-locus coeruleus $\alpha$ (peri-LC $\alpha$ ). Moreover, only the origin of the monoaminergic (Semba, 1993), glutamatergic (Lai et al., 1993) and cholinergic (Mitani et al., 1988; Shiromani et al., 1988; Quattrochi et al., 1989; Semba et al., 1990; Lai et al., 1993; Semba, 1993) afferents were studied. We therefore attempted to determine the specific GABAergic and non-GABAergic afferents to the rat SLD using cholera-toxin B subunit $(\mathrm{CTb})$ which is known to be a more sensitive retrograde tracer than WGA-HRP or fluorogold (Luppi et al., 1990). 


\section{Material and Methods}

\section{Retrograde tracing experiments}

To localize the GABAergic and non-GABAergic afferents to the SLD, two different protocols were used. In a first series of rats, CTb was ejected in the sites in which bicuculline or gabazine microiontophoresis induced a PS-like state. A second series of animals received CTb ejections in the SLD under anesthesia using stereotaxic coordinates.

\section{Protocol for injecting CTb in bicuculline positive sites in head restrained rats.}

The protocol used has been described in detail in our previous paper (Boissard et al., 2002).

Male Sprague-Dawley rats $(280-320 \mathrm{~g}, \mathrm{n}=6$, IFFA Credo, France) were anesthetized with pentobarbital (45 mg/kg, i.p.) and mounted conventionally in a stereotaxic frame (David Kopf), i.e. with ear- and nose-bars. The bone was exposed and cleaned. The skull was placed at a $15^{\circ}$ angle (nose tilted down) to avoid the transverse sinus overlying the pontine reticular formation during the subsequent electrode penetrations. Three stainless steel screws were fixed in the parietal and frontal parts of the skull and three wire electrodes inserted into the neck muscles to monitor the electroencephalogram (EEG) and the electromyogram (EMG), respectively

The bone was then covered with a thin layer of acrylic cement (Superbond, Sun Med. Co, Japan), except the region overlying the SLD and the lambdoid suture. At this time, the headrestraining system was put in place. It consists of a " $U$ " shaped piece of aluminum with four bolts in each angle cemented to the skull of the rat, that can be easily fixed to a carriage, itself fastened to a commercial stereotaxic apparatus with dummy ear-bars. This device allows a painless stereotaxic restraint with high mechanical stability. The "U" piece fixed to the carriage with four bolts was centered above the SLD entry region and embedded in a mount of dental cement with the EEG 
screws and wires, and their 6-pin connector. After the dental cement dried, the four bolts were then unscrewed from the $\mathrm{U}$, now firmly jointed to the rat's skull. The animal was removed from the stereotaxic apparatus and allowed to recover from surgery and anesthesia for 48 hours, before beginning the habituation to the head-restrained apparatus. While in the head-restrained apparatus, rats are easily able to move their extremities. The head restraining system ( $5 \mathrm{~g}$ weight) was well tolerated by the rats and they were able to feed and drink normally in their home cages.

\section{Training and habituation.}

During 8-10 successive days, repetitive trials of increasing duration were done to well habituate the rats to the restraining and recording systems. A hammock comfortably supported the rat with the head painlessly secured to the restraining frame. At the end of the training period, the rat could stay calm for periods of 5-7 hours during which quiet W, SWS and PS could be recorded. Under pentobarbital anesthesia, a $4 \mathrm{~mm}$ hole was made in the skull above the SLD and the dura was removed under microscopic control the day before the first recording session. The brain surface was cleaned at the beginning of each daily recording session under local lidocaine anesthesia. All animals were housed and cared for according to the National Institute of Health "Guide for the Care and Use of Laboratory Animals" (NIH Publication 80-23). The protocol of this study has been approved by our local ethical committee and the French Ministry of Agriculture (Authorization $\mathrm{n}^{\circ}$ 03-505), and efforts were made to reduce the number of animals used.

\section{Local pharmacology.}

A four barrels micropipette assembly was used. One barrel was filled with bicuculline (10 mM, pH 4, Sigma, France) or gabazine (SR-95531, 5 mM, pH 3.8, Sigma), a second one with 
carbachol (100 mM, pH 4, Sigma), a third one with $0.5 \%$ cholera-toxin B subunit (CTb, List Biological Laboratories, CA, USA) and the last one with $\mathrm{NaCl} 0.9 \%$.

The drugs were dissolved in distilled water and $\mathrm{CTb}$ in phosphate buffer $100 \mathrm{mM} \mathrm{pH} 6.0$. Small retention currents (2-5 nA) were used to avoid leakage of the active substances by diffusion. Current balancing techniques and current tests (Stone, 1985) were routinely done via the salinecontaining barrel.

Before starting the local pharmacology, a single recording glass micropipette (3-5 $\mu \mathrm{m}$ tip diameter) was lowered at the stereotaxic coordinates of the right SLD (Paxinos and Watson, 1997). The micropipettes were placed on the brain surface $3.5 \mathrm{~mm}$ posterior to the lambda, $1.2 \mathrm{~mm}$ lateral to the midline. Neurons specifically active during PS were found $6500-7000 \mu \mathrm{m}$ below brain surface, and $500 \mu \mathrm{m}$ ventral to rostral locus coeruleus nucleus (LC) or mesencephalic trigeminal nucleus (MVE). LC noradrenergic neurons were characterized by their specific activity during waking (Gervasoni et al., 1998). The activity of the MVE neurons was correlated with jaw movements.

After the initial period of localization requiring at least one day of recording, a multibarrel micropipette was lowered into the right SLD every day. After one hour of rest, bicuculline, or gabazine was ejected in the SLD with a current intensity of $100 \mathrm{nA}$ applied for 15-46 min in duration. When a positive effect was obtained, $\mathrm{CTb}$ was then ejected with a current of $1 \mu \mathrm{A} 7 \mathrm{sec}$ on/off during $15 \mathrm{~min}$. Around ten days later, the animal was perfused.

\section{Protocol for injecting CTb in anesthetized rats.}

This experimental protocol has been described in detail in our previous papers (Luppi et al., 1990; Peyron et al., 1996; Peyron et al., 1998a). Briefly, male Sprague-Dawley rats (280-320g, n=8; IFFA Credo, France) were deeply anesthetized with pentobarbital (45mg/kg i.p.) and mounted 
conventionally in a stereotaxic frame (David Kopf, CA, USA), i.e. with ear- and nose-bars. The bone was exposed and cleaned and the skull was placed at a $15^{\circ}$ angle (nose tilted down). A glass micropipette (3-5 mm tip diameter) filled with $0.5 \% \mathrm{CTb}$ (List Biological Laboratories, CA, USA) solution [0.1 M phosphate buffer (PB), $\mathrm{pH}$ 6] was lowered into the SLD according to stereotaxic coordinates and extracellular recordings. The micropipettes were placed on the brain surface 3.5 $\mathrm{mm}$ posterior to the lambda, $1.2 \mathrm{~mm}$ lateral to the midline. The SLD was found $6500-7000 \mu \mathrm{m}$ below brain surface, and $500 \mu \mathrm{m}$ ventral to the rostral locus coeruleus nucleus (LC) or mesencephalic trigeminal nucleus (MEV). LC noradrenergic neurones were characterized in anaesthetized rats by their electrophysiological characteristics (spike shape and duration), distinctive spontaneous, slow and regular firing (around $1 \mathrm{~Hz}$ ) and their sensory-evoked discharge (i.e. foot-pinch test) (Gervasoni et al., 1998). The activity of the MEV neurones was correlated with jaw movements. The tracer was ejected iontophoretically in the SLD by a positive current of $1 \mu \mathrm{A}$ $7 \mathrm{sec}$ on/off during $15 \mathrm{~min}$. After 2-7 days, the animals were perfused.

\section{Protocol for perfusion and immunohistochemistry}

All animals were perfused with a Ringer's lactate solution containing $0.1 \%$ heparine, followed by $500 \mathrm{ml}$ of a fixative composed of $4 \%$ paraformaldehyde and $0.2 \%$ picric acid in $0.1 \mathrm{M}$ phosphate buffer ( $\mathrm{PB}, \mathrm{pH} 7.4)$. The brains were postfixed 2 hours in the same fixative at $4^{\circ} \mathrm{C}$. They were then stored at $4^{\circ} \mathrm{C}$ for at least two days in $30 \%$ sucrose in $0.1 \mathrm{M}$ PB. Then, the brains were rapidly frozen with $\mathrm{CO} 2$ gas. Coronal sections $(25 \mu \mathrm{m})$ were obtained with a cryostat and stored in $0.1 \mathrm{M} \mathrm{PB}, \mathrm{pH} 7.4$ containing $0.9 \% \mathrm{NaCl}, 0.3 \%$ Triton $\mathrm{X}-100$ (PBST) and $0.1 \%$ sodium azide (PBST-Az) for $\mathrm{CTb}$ single stainings and $0.1 \%$ potassium sodium azide (KPBS-Az) for double immunostainings.

For all animals, a single $\mathrm{CTb}$ immunostaining was first done. In this case, the free-floating sections were successively incubated in (1) a goat antiserum to CTb (1:40000 with 2\% BSA; List 
Biological Labs.) over 3-4 days at $4^{\circ} \mathrm{C}$; (2) a biotinylated rabbit anti-goat $\operatorname{IgG}$ (1:2000; Vector Laboratories, CA, USA) for 90 min at room temperature; and (3) an ABC-HRP solution (1:1000; Elite kit, Vector Labs.) for $90 \mathrm{~min}$ at room temperature. Then, the sections were immersed in a 0.05 M Tris- $\mathrm{HCl}$ buffer, $\mathrm{pH}$ 7.6, containing 0.025\% 3,3'-diaminobenzidine-4 HCl (DAB; Sigma), $0.003 \% \mathrm{H}_{2} \mathrm{O}_{2}$, and $0.6 \%$ nickel ammonium sulfate for $15 \mathrm{~min}$ at room temperature. The reaction was stopped by two rinses in PBST-Az. All incubations and rinses were made in PBST-Az except for the DAB.

Double immunostaining experiments were performed on sections from animals which received a $\mathrm{CTb}$ injection under anesthesia. In this case, the free-floating sections stored in KPBS were successively incubated in (1) a 3\% swine serum for 90 min (Life Technologies, MD, USA), (2) a rabbit antiserum to glutamate decarboxylase (GAD) with $1 \%$ of swine serum over 3-4 days at $4^{\circ} \mathrm{C}(1: 8000$; Chemicon International, CA, USA), (3) a goat biotinylated anti-rabbit IgG (1:1000; Vector Labs.); and (4) ABC-HRP (1:1000; Elite kit, Vector Labs.), both for 90 min at room temperature. Then, the sections were immersed in a $0.05 \mathrm{M}$ Tris-HCl buffer, $\mathrm{pH} 7.6$, containing $0.025 \%$ 3,3'-diaminobenzidine-4 $\mathrm{HCl}$ (DAB; Sigma) and $0.003 \% \mathrm{H}_{2} \mathrm{O}_{2}$ for $15 \mathrm{~min}$ at room temperature. The reaction was stopped by two rinses in KPBST. All incubations and rinses were made in KPBST except for the DAB. The GAD-stained sections were then incubated in (1) a goat antiserum to $\mathrm{CTb}\left(1: 20000\right.$ with $2 \%$ BSA; List Biological Labs.) for $3-4$ days at $4{ }^{\circ} \mathrm{C}$; (2) a biotinylated rabbit anti-goat $\operatorname{IgG}$ (1:2000; Vector Labs.) for $90 \mathrm{~min}$ at room temperature; and (3) an ABC-HRP solution (1:1000; Elite kit, Vector Labs.) for $90 \mathrm{~min}$ at room temperature. Then, the sections were immersed in $0.01 \mathrm{M}$ PB buffer, $\mathrm{pH} 6.8$ containing $0.01 \%$ benzidine dihydrochloride (BDHC; Sigma), $0.01 \% \mathrm{H}_{2} \mathrm{O}_{2}$ and $0.025 \%$ sodium nitroprusside for $15 \mathrm{~min}$ at room temperature. The reaction was stopped by four rinses in PB buffer. All incubations and rinses were made in PBST except for the BDHC. To study the distribution of the GAD-immunoreactive cell bodies in the SLD and surrounding structures, some sections of the animals were immunostained only for GAD using the protocol described above. 
All labeled sections were mounted on gelatin-coated slides, dried, dehydrated and coverslipped with Depex.

\section{Anterograde tracing experiments}

Phaseolus vulgaris leucoagglutinin (PHA-L) was injected in four structures found to contain numerous retrogradely labeled cells following $\mathrm{CTb}$ injection in the SLD. A stereotaxic surgical method similar to the retrograde experiments was used, but the injections were made with a flat skull and the aid of brain surface landmarks for stereotaxic orientation. PHA-L $(2.5 \%$ in $0.01 \mathrm{M}$ PBS; Vector Labs.) was iontophoretically injected. Cellular recordings through the injection pipette (10-20 $\mu \mathrm{m}$ tips) aided in localizing target sites. Injections were made with $5 \mu \mathrm{A}$ of pulsed current (4 or 7 seconds on, 4 or 7 seconds off) for $30 \mathrm{~min}$. Animals survived for 7-15 days and were then deeply anesthetized and perfused. The brains were then posfixed and cut into frontal sections as described above for the retrograde experiments. Injections were made in the primary motor area of the frontal cortex and the adjacent hindlimb region of the primary somatosensory area $(n=2)$, the lateral hypothalamic area laterodorsal to the fornix $(n=2)$, the dorsal part of the mesencephalic reticular nucleus $(\mathrm{MRN})(\mathrm{n}=3)$ and the ventrolateral part of the periaqueductal gray $(\mathrm{vlPAG})(\mathrm{n}=$ $3)$.

The free-floating sections were then successively incubated in: (1) a rabbit antiserum to PHA-L (1:5000; DAKO, Denmark) over 3-4 days at $4^{\circ} \mathrm{C}$; (2) a biotinylated goat anti-rabbit IgG (1:2000; Vector Labs.) for 90 min at room temperature; and (3) an ABC-HRP solution (1:1000; Elite kit, Vector Labs.) for $90 \mathrm{~min}$ at room temperature. Then, the sections were immersed in a 0.05 $\mathrm{M}$ Tris-HCl buffer (pH 7.6) containing 0.025\% DAB (Sigma), 0.003\% H2O2 and 0.6\% nickel ammonium sulfate for $15 \mathrm{~min}$ at room temperature. The reaction was stopped by two rinses in PBST-Az. All incubations and rinses were made in PBST except for the DAB. The sections were then mounted on gelatin-coated slides, dried, dehydrated and coverslipped with Depex. 


\section{Analysis of the retrograde labeling}

Drawings of double-immunostained sections (GAD/CTb) were made with a Leitz Orthoplan microscope equipped with an $\mathrm{X} / \mathrm{Y}$ sensitive stage and a video camera connected to a computerized image analysis system (Historag; BIOCOM, France). To precisely determine the location and number of $\mathrm{CTb}$ and $\mathrm{GAD} / \mathrm{CTb}$ stained neurones, we bilaterally plotted and counted $\mathrm{CTb}$ and $\mathrm{GAD} / \mathrm{CTb}$ labelled cells in three SLD injected rats on sections taken every $600 \mu \mathrm{m}$ from the hypothalamus to the medulla oblongata (corresponding to 23 sections per animal). For each structure of interest, the sum of the neurons counted was then calculated. Then, the mean \pm SEM numbers of $\mathrm{CTb}$ and $\mathrm{GAD} / \mathrm{CTb}$ labelled cells were determined for each structure (Table 1). Photomicrographs were taken using a Zeiss microscope and digital system. 


\section{Results}

\section{GABAergic neurones localized in the sublaterodorsal nucleus}

On sections immunostained only for GAD, a substantial number of GAD-immunoreactive neurones was observed in the caudal part of the SLD at the level of the rostral part of the motor trigeminal nucleus (V) and the supratrigeminal nucleus (SUT)(Fig 1B). The rostral part of the SLD contained more GAD-immunoreactive cells (Fig. 1A). A very large number of GAD-immunoreactive neurones was localized at the same level in the laterodorsal tegmental (LDT), dorsal tegmental (DTN) and ventral tegmental nuclei (VTN)(Fig1).

\section{Afferents to the sublaterodorsal nucleus}

\section{Localization of the injection sites}

In six rats, $\mathrm{CTb}$ was ejected in a site in which the iontophoresis of bicuculline or gabazine induced a PS-like state characterized by muscle atonia and EEG activation. In 5 of these rats, ejection of bicuculline or gabazine during $15 \mathrm{~min}$ induced a PS-like state during $19.5 \pm 5.0 \mathrm{~min}$ with a latency of 4.7 $\pm 1.2 \mathrm{~min}$. In a last rat, the bicuculline application was pursued during $46 \mathrm{~min}$. In this case, the PS-like state appeared after a latency of $4.5 \mathrm{~min}$ and lasted $44.5 \mathrm{~min}$. The center of the CTb ejection sites in these animals and in three of the animals which received a CTb ejection under anesthesia was localized in or immediately adjacent to the SLD region just rostral to the V or at the level of the rostral portion of the $\mathrm{V}$ (Fig. 2, 3A, 4KL). In five animals injected under anesthesia, the sites of injection were not in the SLD or the double-immunostaining was not optimal. These animals were not further studied.

In all the other animals $(n=8)$, the distribution of the retrogradely labeled cells from forebrain to medullary structures was similar. The CTb singly-labeled neurons and the GAD and CTb doublelabeled neurons were plotted and counted in the three animals (Figs 2, 3A, 4JK) in which $\mathrm{CTb}$ was 
applied under anesthesia. In these animals, eleven percent of the total number of retrogradely labeled neurons were immunoreactive to GAD.

\section{Distribution of the retrogradely labelled cells (Fig.4, Table 1)}

\section{Forebrain}

In the cortex, respectively a large and a substantial number of GAD-negative retrogradely labelled cells was observed in the primary motor area (Mop) and the supplemental somatosensory area (SSs)(Table 1).

At this level, a large number of GAD-negative retrogradely labelled cells was localized ipsilaterally in the lateral and ventral bed nucleus of the stria terminalis (BST) (Figs 4A) and the central nucleus of the amygdala (CEA) (Figs.3F, 4B) (Table 1). A large number of CTb labelled cells were also distributed in the lateral hypothalamic area (Fig. 4C). Twelve percent of these cells were GADimmunoreactive (Table 1). Finally, a substantial number of retrogradely labelled cells was observed in the posterior hypothalamic area and zona incerta (ZI) (Fig. 4C,D, Table 1). Double-labelled neurones were only observed in the zona incerta (23\% of the neurones). Finally, respectively a small and a few number of singly-retrogradely labeled cells was observed in the lateral preoptic area and the magnocellular preoptic nucleus (Fig. 4A).

\section{Mesencephalon and pons}

In the mesencephalon, a very large number of retrogradely labelled cells was observed ipsilaterally in the lateral and ventrolateral periaqueductal gray and with an ipsilateral predominance in the mesencephalic reticular nucleus (MRN)(Fig. 4E-H). Seventeen percent of the cells in the latter structure were immunoreactive to GAD (Fig. 3E)(Table 1). 
The rostral part of the ventral and lateral periaqueductal gray at the level of the red nucleus and the oculumotor nucleus (Fig. 4E-F) contain substantially less CTb-labelled neurones than the ventral and lateral periaqueductal gray at the level of the dorsal raphe nucleus (DR) (Fig. 4 F-I). The retrogradely labeled cells localized in the periaqueductal gray were rarely GAD-positive (Figs. 3D, 4 F-I, Table 1).

At mesencephalic level, a small number of retrogradely labelled cells of which $42 \%$ were GADpositive was also localized ipsilaterally in the substantia nigra, reticular part (Fig. 4E, Table 1). The ventral tegmental area (Fig. 4E, Table 1) and the dorsal raphe nucleus (Fig. 4H-J, Table 1) contained a small number of GAD-negative retrogradely labelled cells.

At pontine level, a very large number of cells was distributed with an ipsilateral predominance in the rostral (PRNr) and caudal (PRNc) pontine reticular nuclei (Fig. 4J-M, Table 1). Respectively 18 and $15 \%$ of these neurones were GAD-immunoreactive (Fig. 3E). The lateral parabrachial nucleus contained ipsilaterally a small number of GAD-negative retrogradely labelled cells (Fig. 4L). At this level, the Kölliker-Fuse nucleus contained ipsilaterally a substantial number of singly retrogradely-labeled cells.

The superior colliculus, locus coeruleus and laterodorsal tegmental nuclei contained a small number of GAD-negative retrogradely labelled cells (Fig 4, Table 1). Finally, the pedunculopontine and controlateral SLD contained a small number of retrogradely labelled cells, $28 \%$ of which were GAD-positive (Fig. 4, Table 1).

\section{Medulla}

Respectively a large and a very large number of retrogradely labelled cells was localized in the lateral paragigantocellular (PGRNl) and parvicellular (PARN) reticular nuclei (Fig. 4N-P, Table 1). Respectively, 16 and $18 \%$ of these cells were GAD-immunoreactive. A substantial number of retrogradely labeled cells was also observed bilaterally in the medial vestibular nucleus (MV)(Fig. 
4M). Finally, a small number of retrogradely labelled cells was localized in the parvicellular alpha reticular (PARNA), raphe magnus (RM), gigantocellular reticular (GRN), magnocellular reticular (MARN) and dorsal paragigantocellular reticular (PGRNd) nuclei (Figs.4L-N, Table 1). Twenty to $53 \%$ of the neurones localized in these structures were GAD-immunoreactive (Table 1). Finally, a small number of GAD-negative retrogradely labeled cells was localized in the nucleus of the solitary tract (NTS) and the spinal trigeminal nucleus (SPV)(Fig. 4N-P, Table 1).

\section{Anterograde tracing}

Following PHA-L injection in the mesencephalic reticular nucleus region just ventral to the ventrolateral periaqueductal gray at the level of the caudal oculomotor nucleus (Fig 5A) or that of the trochlear motor nucleus, a large number of anterogradely labelled fibers was observed in the SLD (Fig 5B). A substantial number of fibers was also localized in the laterodorsal tegmental nucleus (Fig. 5B).

A large number of anterogradely labelled fibers was visible in the SLD (Fig. 5D) following PHA-L injection in the ventrolateral periaqueductal gray at the level of the dorsal raphe nucleus (Fig. 5C) and the trochlear motor nucleus. More fibers were localized in the pontine periaqueductal gray in particular the Barrington's nucleus (Fig 5D).

Following PHA-L injection in the lateral hypothalamic area, a substantial number of anterogradely labelled fibers was observed in the SLD (Fig. 5E).

Finally, a substantial number of anterogradely-labeled fibers was seen in the SLD and the laterodorsal tegmental nucleus (Fig 5F) following PHA-L injection in the primary motor area of the frontal cortex. 


\section{Discussion}

In the present study, we determined for the first time the GABAergic and non-GABAergic afferents to the rat sublaterodorsal nucleus, a nucleus we recently identified as a PS-inducing structure $\{$ Boissard, $2002 \# 1590\}$ which corresponds to the cat peri-LC . $\quad . .1 \quad$. $\quad$. We found that, in addition to interneurones, the GABAergic innervation of the SLD arises mainly from the mesencephalic, rostral and caudal pontine reticular nuclei. We further observed strong nonGABAergic afferents from these structures, the primary motor area of the frontal cortex, the central nucleus of the amygdala, lateral and ventral bed nucleus of the stria terminalis, lateral hypothalamic area, lateral and ventrolateral periaqueductal gray and the lateral paragigantocellular reticular nucleus. Although the afferents to the pontine PS-inducing region have already been studied in cats (Leichnetz et al., 1989; Quattrochi et al., 1989; Lai et al., 1993) and rats (Shammah-Lagnado et al., 1987; Semba, 1993) using HRP or WGA-HRP, the sites of injection obtained were large and centered on the pontine reticular nucleus (PRN) region ventral to the SLD. Further, only one of these studies described the afferents from the entire neuroaxis (Shammah-Lagnado et al., 1987) and the GABAergic afferents were not determined. It is therefore not surprising that several of the afferents to the SLD reported here are common with those reported for the PRN, while others are specific to the SLD or PRN. The most significant difference between our study and the previous ones is the weaker projections from the zona incerta, superior colliculus, contralateral PRN, deep cerebellar and vestibular nuclei. Anterograde tracing studies using PHA-L or H3 leucine also showed that the zona incerta, the fields of Forel (Ricardo, 1981; Watanabe \& Kawana, 1982) and the superior colliculus (Graham, 1977)(Moschovakis et al., 1998) project more strongly to the PRN than to the SLD. In addition, neurons with an activity correlated with eyes and/or head movements have been recorded in these structures and the PRN but not in the SLD (Siegel, 1979; Siegel \& Tomaszewski, 1983; Review in Moschovakis et al., 1996). Further, we have previously shown that iontophoretic application of bicuculline in the PRN just ventral to the SLD induces an increase in 
phasic and tonic muscle activities whereas bicuculline ejection in the SLD induces muscle atonia (Boissard et al., 2002). Altogether these data indicate that the PRN region ventral to the SLD is involved in the coordination of eyes, head and body movement whereas the SLD is specifically involved in PS and the associated muscle atonia. The present study is therefore the first study specifically describing the afferents to the pontine region inducing PS. We discuss below our results in detail for each afferent described.

\section{Reticular afferents}

We observed numerous retrogradely labelled cells in several subdivisions of the mesencephalic, pontine and medullary reticular formation. This is not surprising since it is well known from the pioneering Golgi work of Sheibel and Sheibel (1958) that reticular neurones main projections are directed to reticular neurones at other levels of the reticular formation. However, the localization of the reticular neurones retrogradely labelled in our study differ in several cases from that observed in studies on the PRN indicating the existence of a topographical organization of the reticulo-reticular projections.

A very large number of retrogradely labelled neurones was seen in the mesencephalic reticular nucleus particularly its subdivision just ventral to the periaqueductal gray following injection of retrograde tracers in the SLD (present study) or the cat and rat PRN (Shammah-Lagnado et al., 1987; Lai et al., 1993; Semba, 1993). Anterograde tracing experiments in cats (Graybiel, 1977) and rats (Jones \& Yang, 1985) using H3 leucine confirmed the existence of a strong projection from the mesencephalic reticular nucleus to the PRN and SLD. We found that $17 \%$ of the mesencephalic reticular nucleus neurones projecting to the SLD were immunoreactive to GABA while Lai et al. found in cats that $47 \%$ of the mesencephalic reticular nucleus neurones projecting to the PRN were immunoreactive to glutamate. Additional studies are necessary to determine whether the non- 
GABAergic component of the projection from the mesencephalic reticular nucleus to the SLD is also glutamatergic in nature.

Following CTb injection in the SLD, respectively a small and a large number of GABAergic and non-GABAergic cells were retrogradely labelled in the contralateral SLD and diffusely in the ipsi and contralateral PRN. In contrast, ejection of retrograde tracers in the rat or cat PRN produced a strong retrograde labeling in the exact mirror area of the contralateral PRN as well as in its most ventral part (Shammah-Lagnado et al., 1987; Lai et al., 1993; Semba, 1993). Contralateral in mirror projection of PRN neurones has been confirmed by anterograde tracing with $\mathrm{H} 3$ leucine in rats (Jones \& Yang, 1985) and cats (Graybiel, 1977; Robertson \& Feiner, 1982). A precise anterograde tracing study on the projection from the contralateral PRN to the SLD is still lacking.

We further found that the projection from the PRN to the SLD is in part GABAergic (16 to $20 \%$ of the retrogradely labelled neurones) while Lai and Siegel (1993) reported in cats that as much as $90 \%$ of the neurones retrogradely labelled in the contralateral PRN following WGA-HRP injection in the PRN were immunoreactive to glutamate. Moreover, previous electrophysiological studies showed that contralateral excitatory projections could be predominant at least for some subregions of the PRN (McCarley et al., 1987). Additional studies are therefore necessary to determine whether the non-GABAergic neurons from the PRN projecting to the SLD are glutamatergic.

A large number of retrogradely labelled cells was also observed in parvicellular and lateral paragigantocellular reticular nuclei following CTb injection in the SLD while only a small number of cells was seen following WGA-HRP injections in the PRN (Shammah-Lagnado et al., 1987; Semba, 1993). Strong projections from these structures to the SLD but not the PRN have been confirmed by anterograde tracing using H3 leucine injections \{Loewy, 1981 \#981\}\{Jones, 1985 $\# 83\}$. 


\section{Afferents from the periaqueductal gray}

We observed a strong projection from the ventrolateral and lateral periaqueductal gray to the SLD and others reported a strong projection from this structure to the rat and cat PRN (ShammahLagnado et al., 1987; Lai et al., 1993; Semba, 1993).Such dense projection to the SLD and PRN has been confirmed in rats and cats by anterograde tracing using PHA-L or H3 leucine (Shaikh et al., 1987; Cameron et al., 1995; Krout et al., 1998; Bajic \& Proudfit, 1999). We further found that the neurones from the periaqueductal gray projecting to the SLD are GAD-negative while Lai and Siegel (1993) reported in cats that $32 \%$ of the neurones from the periaqueductal gray projecting to the PRN are immunoreactive to glutamate. At least part of the neurons from the periaqueductal gray projecting to the SLD could therefore use glutamate as a neurotransmitter.

\section{Substantia nigra}

We observed a small number of retrogradely labelled cells in the substantia nigra reticular part (SNr) following CTb injections in the SLD. Forty-two percent of these cells were immunoreactive

to GABA. A few retrogradely labelled cells was observed in this nucleus following injection of WGA-HRP in the PRN (Shammah-Lagnado et al., 1987). Following PHA-L injection in the lateral part of the substantia nigra, reticular part, a substantial number of anterogradely labelled fibers was localized in the SLD (Yasui et al., 1992) confirming the specificity of the projection revealed in the present study.

\section{Limbic and hypothalamic structures}

We observed a large number of retrogradely labelled cells in the central nucleus of the amygdala, the ventral and lateral parts of the bed nucleus of the stria terminalis and the lateral hypothalamic 
area following CTb injection in the SLD . A small number of cells was observed in these structures following injection of WGA-HRP in the PRN (Shammah-Lagnado et al., 1987). The specificity of these projections to the SLD is strongly supported by anterograde studies demonstrating numerous anterogradely labelled fibers in the SLD following injection of PHA-L or H3 leucine in cat or rat central nucleus of the amygdala (Hopkins \& Holstege, 1978; Van Bockstaele et al., 1996), bed nucleus of the stria terminalis (Holstege et al., 1985) and lateral hypothalamic area (our study and Holstege, 1987; Allen \& Cechetto, 1992).

We found that the projections from the bed nucleus of the stria terminalis and the central nucleus of the amygdala to the SLD are not GABAergic. Additional work is necessary to determine their neurotransmitter content.

Approximately $12 \%$ of the retrogradely labelled neurones localized in the lateral hypothalamic area were immunoreactive to GABA. The neurochemical identity of the remaining neurones remains to be identified. Part of them could contain hypocretin since hypocretin neurons are localized in the lateral hypothalamic area and hypocretin-immunoreactive fibers have been observed in the SLD (Peyron et al., 1998b).

\section{Monoaminergic and cholinergic nuclei}

We also observed a small number of retrogradely labelled neurones in the dorsal raphe nucleus and the locus coeruleus and a few in the tuberomammillary nucleus following CTb injection in the SLD. These neurons could be respectively serotonergic, noradrenergic and histaminergic. Indeed, it has been shown that the adjacent PRN receives noradrenergic, serotonergic and histaminergic inputs from these nuclei (Semba, 1993).

We observed a small number of retrogradely-labeled cells in the laterodorsal tegmental and pedunculopontine nuclei following CTb injections in the SLD. Small to substantial projections from these nuclei to the PRN was previously described in rats (Semba et al., 1990; Semba, 1993) and cats 
(Mitani et al., 1988; Shiromani et al., 1988; Quattrochi et al., 1989; Lai et al., 1993). Combining cholineacetyltransferase and glutamate immunohistochemistry with retrograde labeling, it was further demonstrated that these projections are in part cholinergic and glutamatergic. Further studies are necessary to determine whether the projections from the laterodorsal tegmental and pedunculopontine nuclei to the SLD are also in part cholinergic or glutamatergic since only a few of these neurons are GABAergic.

\section{Physiological significance}

We recently demonstrated that iontophoretic application of bicuculline, gabazine and kainic acid in the SLD but not that of carbachol induces a PS-like state characterized by complete muscle atonia, EEG activation and increase in theta activity (Boissard et al., 2002). From these results, we hypothesized that PS-on executive neurones from the SLD are under a tonic GABAergic inhibition both during W and SWS. GABAergic desinhibition and glutamate excitation would play a crucial role in their activation at the onset of and during PS while acetylcholine would play only a minor role. This is at variance with data obtained in cats which indicate since the sixties a predominant role of acetylcholine (George et al., 1964) in the activation of the pontine PS-on neurons and only recently introduced the idea that glutamate (Lai \& Siegel, 1991; Onoe \& Sakai, 1995) and GABA (Xi et al., 1999a; b; 2001) might also play an important role. The aim of the present study was therefore to localize the GABAergic and non-GABAergic potentially excitatory neurones controlling the PS-on neurones localized in the SLD. Indeed, even if the GABAergic innervation generally arises from interneurones, the existence of long GABAergic projection systems is now well accepted.

Our results indicate that the GABAergic innervation of SLD neurones indeed arises both from interneurones and distant neurons localized in the mesencephalic and pontine reticular nuclei and to a minor extent the parvicellular reticular nucleus. A recent study by Xi et al. (1999a) 
suggested that interneurones might be the best candidates for the inhibition of PS-on SLD neurones. Indeed, they found that administration of antisense oligonucleotides against glutamic acid decarboxylase (GAD) mRNA into the cat dorsal part of the nucleus pontis oralis (corresponding to the cat peri-LC $\alpha$ and the rat SLD) produces a significant decrease in W and an increase in PS (Xi et al., 1999a). Besides, Maloney et al. (2000) found in rats that the number of c-Fos expressing GABAergic neurones in the rostral pontine reticular nucleus decreases following PS rebound suggesting that GABAergic neurones from this structure are active during W and SWS and inactive during PS. From these and our results, we hypothesize that GABAergic neurones localized in the SLD but also diffusely in the mesencephalic and pontine reticular nuclei innervate SLD PS-on neurones and tonically inhibit them during W and SWS. Additional studies are necessary to confirm that these populations of GABAergic neurones directly project on PS-on neurones from the SLD and are inactive during PS (PS-off neurones).

In addition to GABAergic inputs, we observed strong non-GABAergic inputs to the SLD from the primary motor area of the frontal cortex, the bed nucleus of the stria terminalis, central nucleus of the amygdala, lateral hypothalamic area, lateral and ventrolateral periaqueductal gray, mesencephalic and pontine reticular nuclei and the parvicellular and lateral paragigantocellular reticular nuclei. Neurons from these structures might project to SLD PS-on neurons, GABAergic interneurones or other uncharacterized classes of neurons.

The non-GABAergic projection to the SLD from the lateral and ventrolateral periaqueductal gray and the mesencephalic reticular nucleus region just ventral to it likely terminates on GABAergic interneurons and contributes to the inhibition of PS-on neurones from the SLD during W and SWS. Indeed, it has been shown in cats by Sastre et al. (1996; 2000) and by us in rats (Boissard et al., 2000) that reversible inactivation of the neurones from the ventrolateral periaqueductal gray and the mesencephalic reticular nucleus region ventral to it by muscimol injection induces a strong increase in PS quantities. Altogether, these and our results highly suggest that excitatory putatively glutamatergic neurones in the ventrolateral periaqueductal gray and the 
mesencephalic reticular nucleus are tonically active during W and SWS and tonically inhibit PS via their projection to GABAergic PS-off interneurones from the SLD. Additional experiments are necessary to test this hypothesis.

We also found a strong non-GABAergic input to the SLD from the central nucleus of the amygdala and the ventral and lateral bed nucleus of the stria terminalis. Interestingly, Maquet et al (1996) found that regional cerebral blood flow is positively correlated with PS in the amygdaloid complex. Further, electrical stimulation of the central nucleus of the amygdala increases the frequency of PGO waves recorded in or just dorsal to the SLD (Deboer et al., 1998). From these and our results, it might be hypothesized that the central nucleus of the amygdala and the bed nucleus of the stria terminalis provide excitatory projections to PS-on neurones from the SLD. Further experiments are necessary to determine whether the neurons from these limbic structures directly project and excite PS-on neurons from the SLD and are specifically active during PS.

Finally, we found only small projections from the dorsal paragigantocellular and magnocellular reticular nuclei to the SLD. These results suggest that these two structures hypothesized to respectively contain the GABAergic and the glycinergic neurones responsible for the inhibition of LC noradrenergic neurones (Luppi et al., 1999) and the somatic motoneurones (Boissard et al., 2002) during PS play minor roles in the control of PS-on neurones from the SLD.

In conclusion, based on our present neuroanatomical and previous pharmacological results (Boissard et al., 2002), we propose that GABAergic neurones localized in the SLD itself and the mesencephalic and pontine reticular nuclei tonically inhibit the PS-on neurons from the SLD during W and SWS. Non-GABAergic possibly excitatory projections to the SLD from the same structures, the ventrolateral periaqueductal gray, bed nucleus of the stria terminalis, central nucleus of the amygdala, lateral hypothalamic area and primary motor area of the frontal cortex could either directly terminate on PS-on neurons and contribute to their activation during PS or terminate on GABAergic interneurones and indirectly inhibit the PS-on neurons during W and SWS. 


\section{Acknowledgments}

This work was supported by INSERM (U480), CNRS (CNRS FRE2469) and Université Claude Bernard Lyon I. Romuald Boissard received a $\mathrm{PhD}$ grant from the Fondation pour la Recherche

Médicale. The authors wish to thank C. Guillemort (GFG Co, Pierre-Bénite, France) for his help in designing the head-restraining system.

\section{Abbreviations}

BDHC: benzidine dihydrochloride

BST: bed nucleus of the stria terminalis

CEA: central nucleus of the amygdala

$\mathrm{CTb}$ : cholera-toxin B subunit

DAB: 3,3'-diaminobenzidine-4 $\mathrm{HCl}$

DR: dorsal raphe nucleus

EEG: electroencephalogram

GAD: glutamate decarboxylase

KBST-Az: potassium buffer saline Triton $\mathrm{X}$ azide

LC: locus coeruleus

LDT: laterodorsal tegmental nucleus

MARN: magnocellular reticular nucleus

MEV: mesencephalic trigeminal nucleus

MRN: mesencephalic reticular nucleus

PAG: periaqueductal gray

PARN: parvicellular reticular nucleus

PB: phosphate buffer

PBST: phosphate buffer saline Triton X

PBST-Az: phosphate buffer saline Triton X azide 
peri-LC $\alpha$ : peri-locus coeruleus $\alpha$

PGRNd: dorsal paragigantocellular reticular nucleus

PGRNl: lateral paragigantocellular reticular nucleus

PHA-L: phaseolus vulgaris leucoagglutinin

PPN: pedunculopontine nucleus

PRN: pontine reticular nucleus

PRNc: caudal pontine reticular nucleus

PRNr: rostral pontine reticular nucleus

PS: paradoxical sleep

PS-like: paradoxical sleep-like

RM: raphe magnus nucleus

SLD: sublaterodorsal nucleus

SNr: substantia nigra reticular part

SWS: slow wave sleep

$\mathrm{V}$ : motor trigeminal nucleus

V1PAG: ventrolateral part of the periaqueductal gray

W: wake

ZI: zona incerta 


\section{Figure 1:}
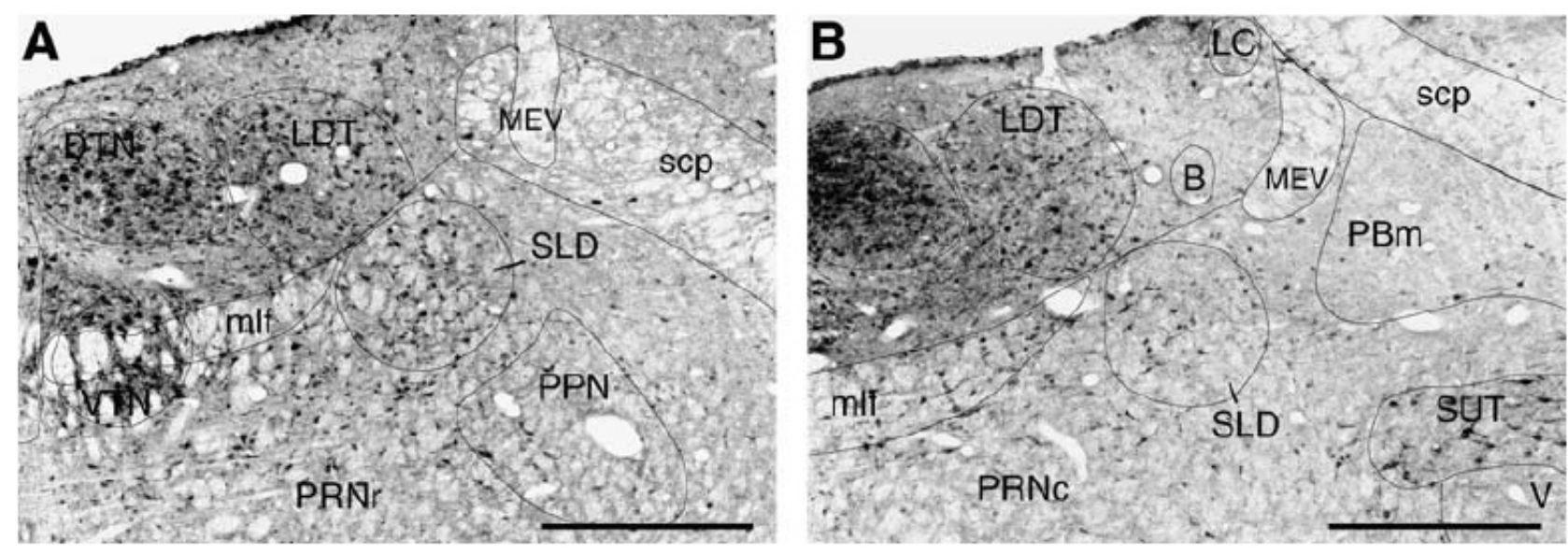

Photomicrographs illustrating GAD-immunoreactive neurones in the rostral (A) and caudal parts (B) of the SLD. The caudal SLD localized at the level of the rostral trigeminal nucleus (V) and the supratrigeminal nucleus (SUT) contained a relatively small number of GAD-immunoreactive cells. The rostral SLD localized at the caudal level of the ventral tegmental nucleus contained a large number of GAD-immunoreactive cells. The laterodorsal tegmental nucleus, the dorsal tegmental nucleus and the ventral tegmental nucleus at the same level contained a very large number of GADimmunoreactive cells. Bars $=250 \mu \mathrm{m}$. Abbreviations: DTN, dorsal tegmental nucleus; LDT, laterodorsal tegmental nucleus; SLD: sublaterodorsal nucleus; SUT, supratrigeminal nucleus; VTN, ventral tegmental nucleus. 


\section{Figure 2:}

\section{- $\mathrm{CTb} / \mathrm{GAD}$}

\section{- $\quad \mathrm{CTb}$ in PS inducing sites}
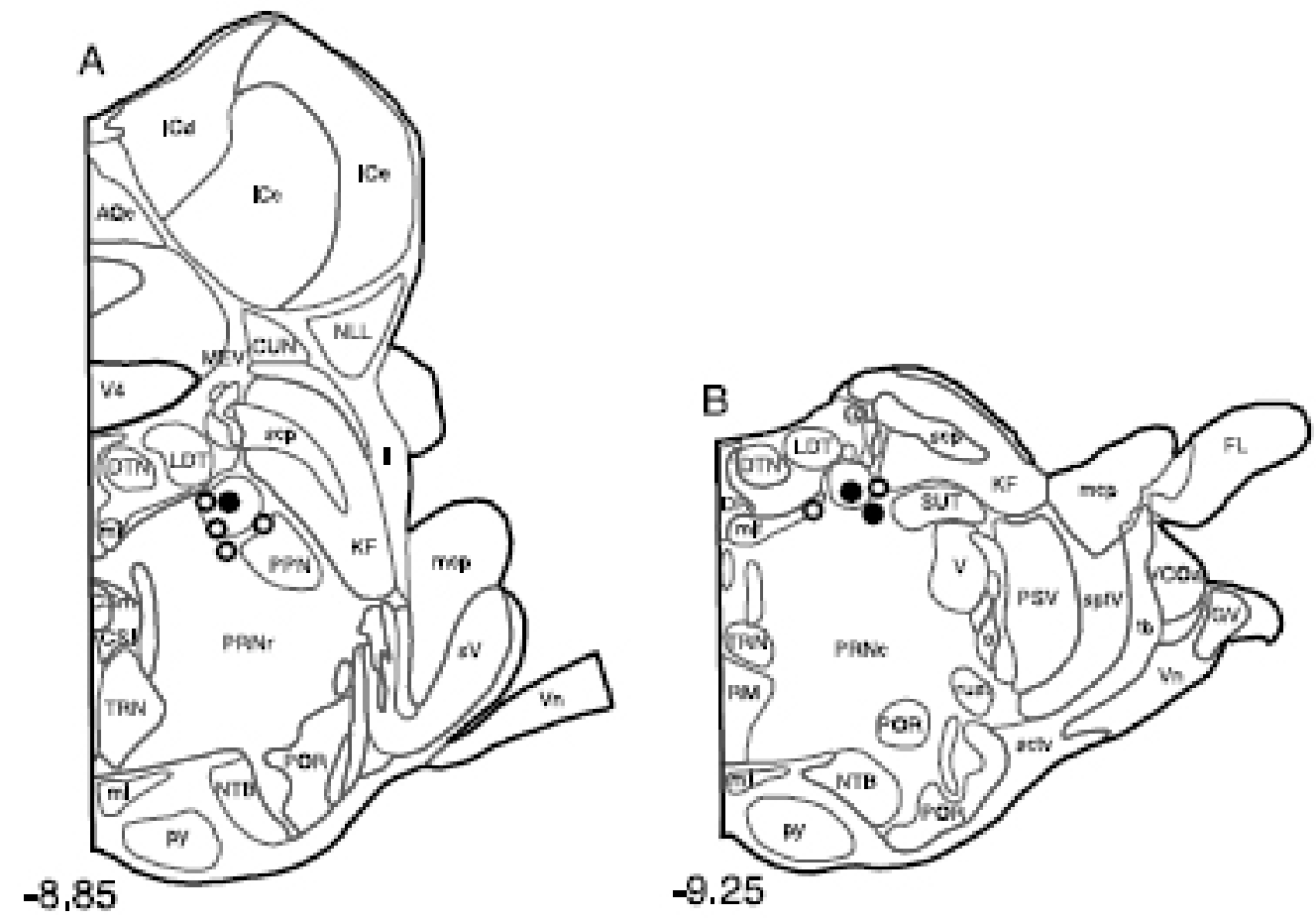

Schematic representations of $\mathrm{CTb}$ injection sites in the SLD. Line drawings of coronal sections at two different levels of the brainstem are from the stereotaxic atlas of Swanson (1992). Each dot represents a $\mathrm{CTb}$ injection site. Open circles indicate the $\mathrm{CTb}$ injection sites obtained in animals in which bicuculline or gabazine iontophoresis in the SLD induced a PS-like state, and closed circles indicate the $\mathrm{CTb}$ injection sites obtained in anesthetized animals. Abbreviations: AQ, cerebral aqueduct; Aqc, cerebral aqueduct, collicular recess; B, Barrington's nucleus; cic, commissure of the inferior colliculus; CSl, lateral superior central nucleus raphe; CSm, medial superior central nucleus raphe; cst, corticospinal tract; CUN, cuneiform nucleus; DR, dorsal nucleus raphé; DTN, dorsal tegmental nucleus; ICd, inferior colliculus, dorsal nucleus; ICe, inferior colliculus, external nucleus; FL, flocculus; GV, trigeminal ganglion; KF, Kölliker-Fuse subnucleus; LC, locus coeruleus nucleus; LDT, laterodorsal tegmental nucleus; 11, lateral lemniscus; mcp, middle cerebellar peduncle; MEV, mesencephalic nucleus of the trigeminal; ml, medial lemniscus; mlf, medial 
longitudinal fascicle; NLL, nucleus of the lateral lemniscus; NTB, nucleus of the trapezoid body; PAG, periaqueductal gray; PBm, medial parabrachial nucleus; PG, pontine gray; POR, periolivary nuclei; PPN, pedunculopontine nucleus; PRNc, caudal pontine reticular nucleus; PRNr, rostral pontine reticular nucleus; PSV, principal sensory nucleus of the trigeminal; py, pyramidal tract; RM, nucleus raphé magnus; rust, rubrospinal tract; scp, superior cerebellar peduncle; sctv, ventral spinocerebellar tract; $\mathrm{SOCl}$, lateral superior olivary complex; $\mathrm{sptV}$, spinal tract of the trigeminal nerve; SUT, supratrigeminal nucleus; sV, sensory root of the trigeminal nerve; tb, trapezoid body; TRN, tegmental reticular nucleus; V, motor nucleus of the trigeminal nerve; V4, 4th ventricle; VCOa, anterior ventral cochlear nucleus; VIIn, facial nerve; VIIIn, vestibulocochlear nerve; Vn, trigeminal nerve; VTN, ventral tegmental nucleus. 


\section{Figure 3:}

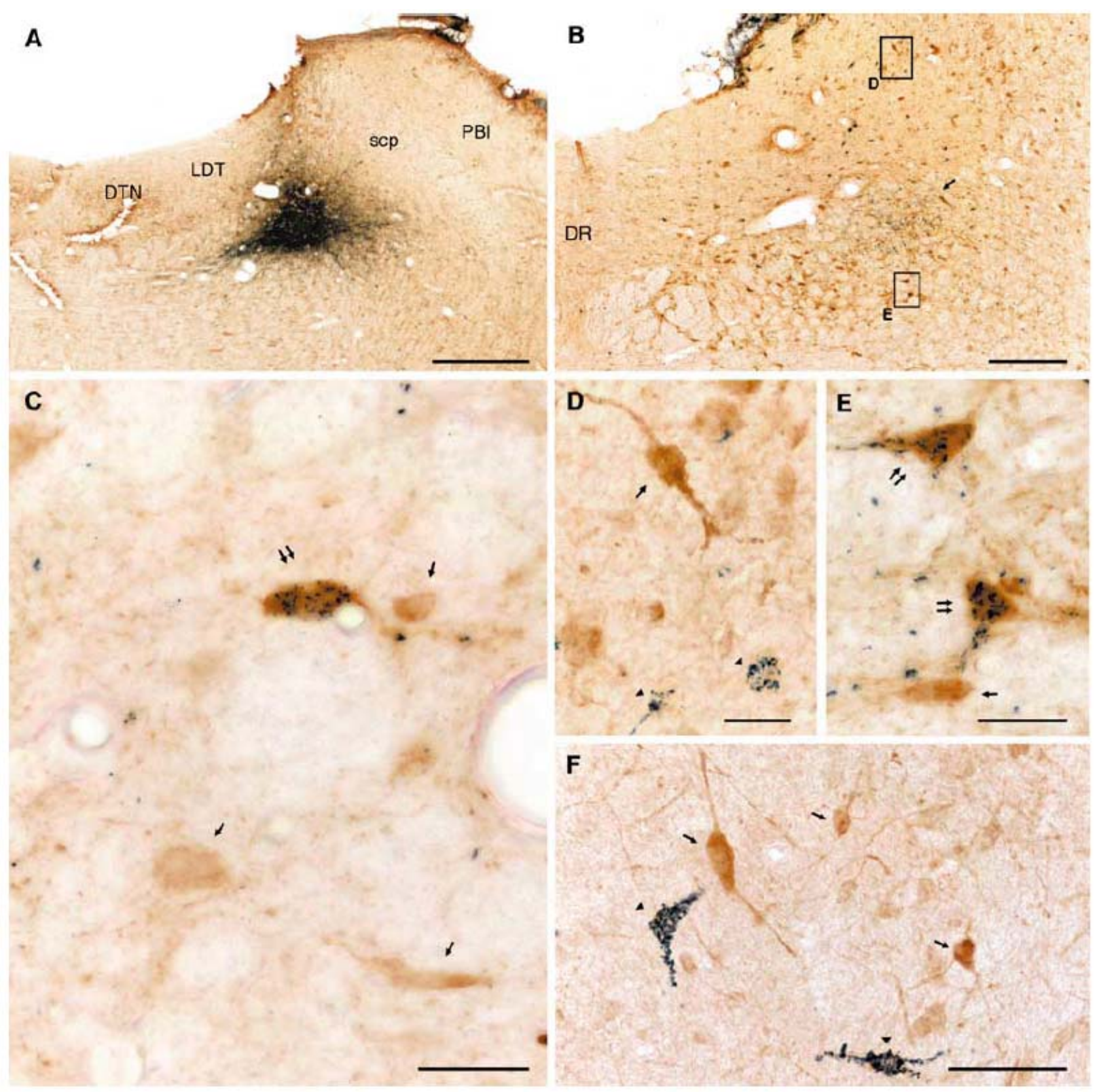

A: Photomicrograph illustrating a representative $\mathrm{CTb}$ injection site in the rostral SLD. Bars $=500 \mu \mathrm{m}$. B: Low power photomicrograph illustrating a section double-stained with GAD and $\mathrm{CTb}$ at the level of the ventrolateral periaqueductal gray and the dorsal mesencephalic reticular nucleus following a $\mathrm{CTb}$ injection restricted to the SLD. Numerous GAD-immunoreactive neurones labelled in brown are visible in the medial portion of the dorsal part of the mesencephalic reticular nucleus. Note also the presence of a bundle of $\mathrm{CTb}$ anterogradely labelled fibers in the dorsal mesencephalic reticular nucleus (arrow) Bars $=250 \mu \mathrm{m}$. C: High power photomicrograph illustrating a $\mathrm{CTb}$ and GAD double immunostained neurone (double arrow) and GAD-singly labeled neurons 
(arrows) localized in the rostral pontine reticular nucleus. Bars $=25 \mu \mathrm{m}$. D and E: enlargements of the sections shown in B illustrating single GAD (arrow) and CTb labelled cells (arrowheads) in D and two double-immunostained neurones (double arrows) in E. Bars $=25 \mu \mathrm{m}$. F: Photomicrographs illustrating singly GAD immunoreactive neurones in brown (arrows) and singly retrogradely labelled neurones (with blue-black granules in the cytoplasm) (arrowheads) in the central nucleus of the amygdala following a CTb injection in the SLD. Bars $=100 \mu \mathrm{m}$. 


\section{Figure 4:}
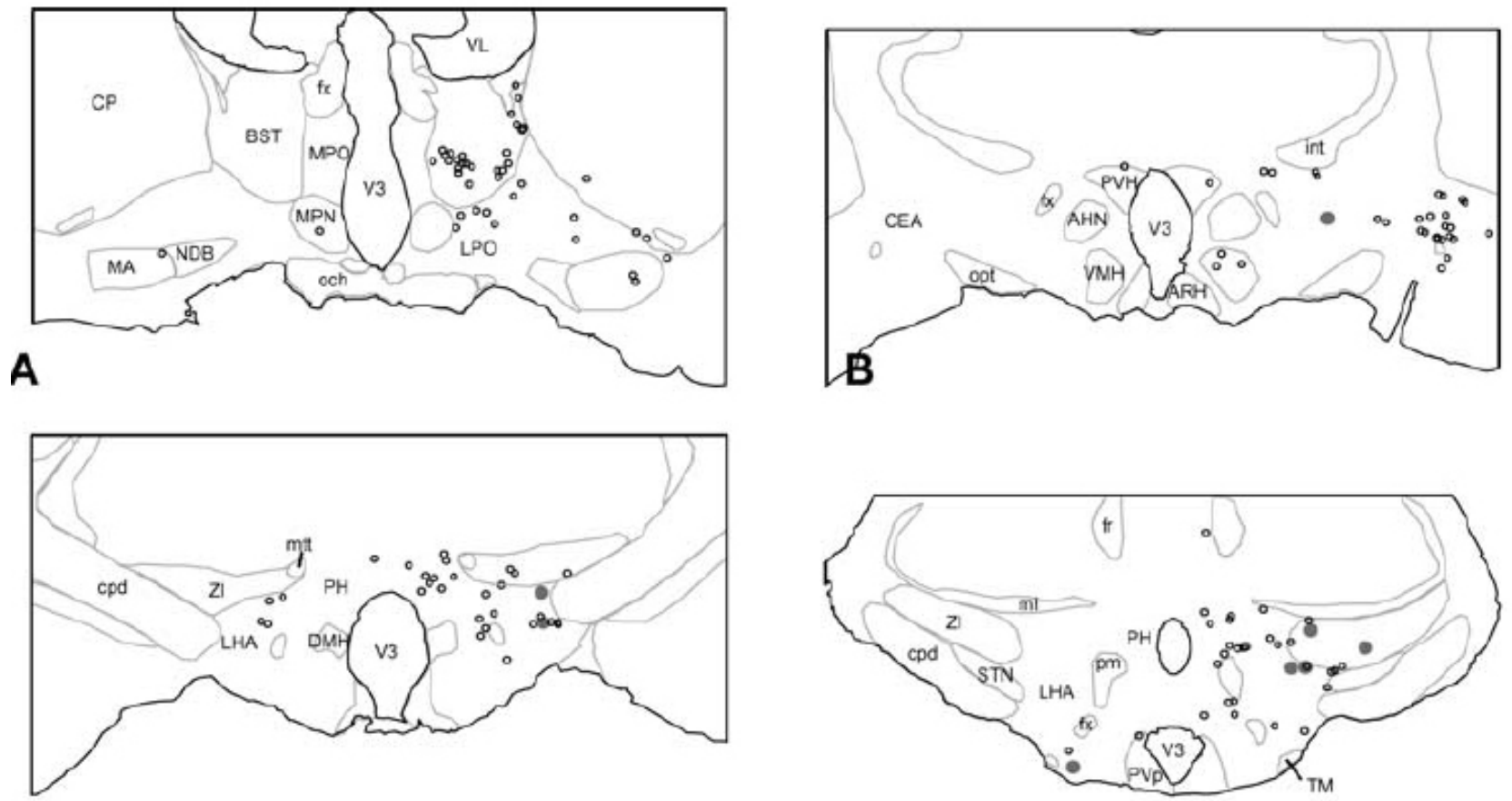

C

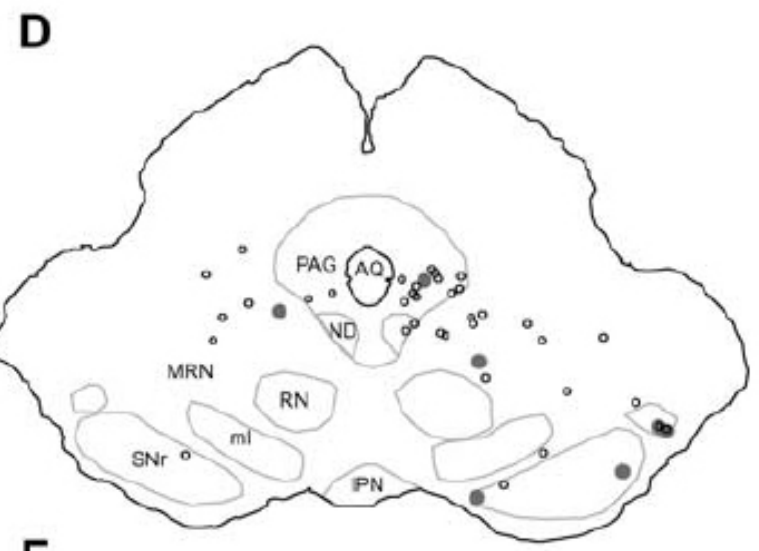

E

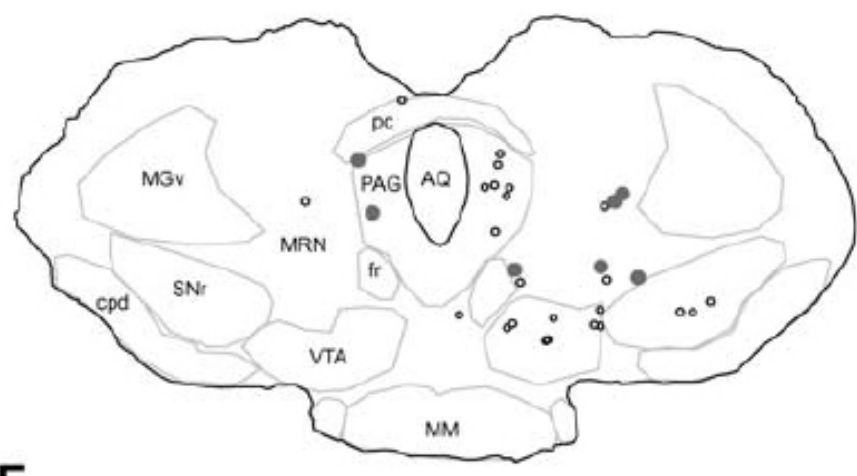

$\mathrm{F}$
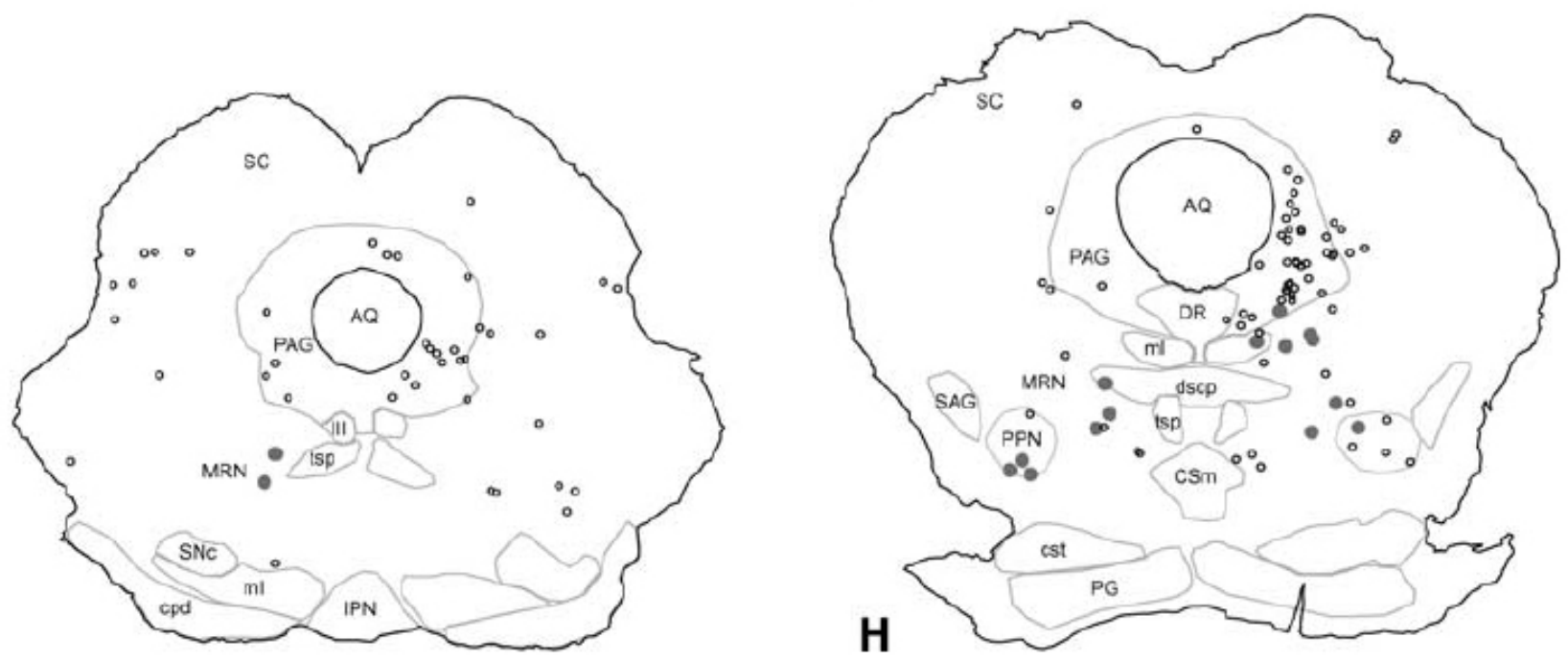

Schematic drawings of $\mathrm{CTb} / \mathrm{GAD}$ double labelled cells (filled circles) and $\mathrm{CTb}$ singly labelled cells (small open circles) on $25 \mu \mathrm{m}$ frontal medullary sections from rostral to caudal structures from an 
animal with a CTb injection into the SLD. Abbreviations: AHN, anterior hypothalamus nucleus; $\mathrm{AMB}$, nucleus ambiguus; ARH, arcuate nucleus hypothalamus; BST, bed nucleus of the stria terminalis; CEA, central nucleus of the amygdala; CP, caudoputamen; cpd, cerebral peduncle; CSm, medial superior central nucleus raphe; cst, corticospinal tract; CUN, cuneiform nucleus; CVL, caudoventrolateral reticular nucleus; DMH, dorsomedial nucleus hypothalamus; DR, dorsal raphe nucleus; dscp, decussation of the superior cerebellar peduncle; DTN, dorsal tegmental nucleus; fx, columns of the fornix; GRN, gigantocellular reticular nucleus; IC, inferior colliculus; icp, inferior cerebellar peduncle; III, oculomotor nucleus; int, internal capsule; IO, inferior olivary complex; IPN, interpeduncular nucleus; KF, Kölliker-Fuse subnucleus; LDT, laterodorsal tegmental nucleus; LHA, lateral hypothalamic area; MA, magnocellular preoptic nucleus; MARN, magnocellular reticular nucleus; ml, medial lemniscus; MPN, medial preoptic nucleus; MPO, medial preoptic area; MRN, mesencephalic reticular nucleus; MV, medial vestibular nucleus; ND, nucleus of Darkschewitsch; NLL, nucleus of the lateral lemniscus; NTB, nucleus of the trapezoid body; NTS, nucleus of the trapezoid body; opt, optic tract; PAG, periaqueductal gray; PARN, parvicellular reticular nucleus; PARNA, parvicellular reticular nucleus alpha; PB1, lateral parabrachial nucleus; PG, pontine gray; PGRNd, dorsal paragigantocellular reticular nucleus; PGRN1, lateral paragigantocellular reticular nucleus; PH, posterior hypothalamic nucleus; pm, principal mammillary tract; POR, periolivary nuclei; PRNc, caudal pontine reticular nucleus; PRNr, rostral pontine reticular nucleus; $\mathrm{PVH}$, paraventricular nucleus hypothalamus; py, pyramidal tract; $\mathrm{RM}$, raphe magnus nucleus; RN, red nucleus; SAG, nucleus sagulum; scp, superior cerebellar peduncle; SLD, sublaterodorsal nucleus; SN, substancia nigra; SOCm, medial superior olivary complex; sptV, spinal tract of the trigeminal nerve; SPVO, oral spinal trigeminal nucleus; SPIV, spinal vestibular nucleus; STN, subthalamic nucleus; SUV, superior vestibular nucleus; tb, trapezoid body; TRN, tegmental reticular nucleus; tsp, tectospinal pathway; V4, 4th ventricle; VI, abducens nucleus; VII, facial nucleus; VIIn, facial nerve; VMH, ventromedial nucleus 
hypothalamus; VTN, ventral tegmental nucleus; vVIIIn, vestibular nerve; XII, hypoglossal nucleus;

ZI, zona incerta.

Table 1. Number of $\mathrm{CTb}$ and $\mathrm{CTb} / \mathrm{GAD}$ labeled cells counted per section in the principal afferents of the SLD ${ }^{\mathrm{a}}$

\begin{tabular}{|c|c|c|c|c|}
\hline Structure & CTb ipsi & $C T b / G A D$ ipsi & $\mathrm{CTb}$ contra & $C T b / G A D$ contra \\
\hline$\overline{\text { Mop }}$ & $21.7 \pm 13.8$ & 0 & $1.3 \pm 2.3$ & 0 \\
\hline SSs & $12.0 \pm 3.5$ & $0.7 \pm 0.6$ & $2.3 \pm 1.2$ & 0 \\
\hline MA & $2.7 \pm 3.8$ & $0.3 \pm 0.6$ & $0.7 \pm 1.2$ & 0 \\
\hline LPO & $8.0 \pm 5.2$ & 0 & $0.7 \pm 0.6$ & 0 \\
\hline BST & $23.7 \pm 14.7$ & $0.3 \pm 0.6$ & $0.3 \pm 0.6$ & $0.3 \pm 0.6$ \\
\hline CEA & $20.0 \pm 3.6$ & 0 & $0.3 \pm 0.6$ & 0 \\
\hline PVH & $0.7 \pm 0.6$ & 0 & $1.0 \pm 1.0$ & 0 \\
\hline ZI & $11.0 \pm 2.6$ & $1.7 \pm 1.5$ & $1.7 \pm 1.5$ & 0 \\
\hline TM & $0.3 \pm 0.6$ & 0 & $1.0 \pm 0.0$ & 0 \\
\hline LHA & $27.7 \pm 15.3$ & $3.3 \pm 0.6$ & $3.3 \pm 4.2$ & $1.0 \pm 1.0$ \\
\hline $\mathrm{PH}$ & $10.7 \pm 8.0$ & 0 & $1.7 \pm 2.9$ & 0 \\
\hline rostPAG & $25.7 \pm 17.9$ & $0.7 \pm 0.6$ & $8.0 \pm 7.2$ & $1.3 \pm 1.2$ \\
\hline DR & $6.0 \pm 3.6$ & 0 & & \\
\hline MRN & $92.3 \pm 23.6$ & $15.3 \pm 5.5$ & $32.0 \pm 16.1$ & $4.3 \pm 2.5$ \\
\hline $\mathrm{SNr}$ & $8.7 \pm 6.1$ & $3.7 \pm 1.5$ & $0.3 \pm 0.6$ & 0 \\
\hline VTA & $6.0 \pm 2.6$ & $0.7 \pm 1.2$ & $0.3 \pm 0.6$ & $0.3 \pm 0.6$ \\
\hline $\mathrm{SC}$ & $7.7 \pm 2.5$ & 0 & $8.0 \pm 2.6$ & 0 \\
\hline dPAG & $8.3 \pm 1.2$ & 0 & $0.7 \pm 1.2$ & 0 \\
\hline vlPAG & $60.3 \pm 20.6$ & $1.0 \pm 0.0$ & $10.7 \pm 4.7$ & 0 \\
\hline PPN & $8.3 \pm 8.1$ & $2.3 \pm 1.5$ & $4.0 \pm 2.6$ & $1.3 \pm 1.5$ \\
\hline IC & $0.3 \pm 0.6$ & 0 & $0.7 \pm 0.6$ & $0.3 \pm 0.6$ \\
\hline LDT & $3.7 \pm 2.1$ & $0.3 \pm 0.6$ & $2.0 \pm 1.0$ & 0 \\
\hline $\mathrm{PB} 1$ & $8.0 \pm 4.6$ & 0 & $1.3 \pm 1.5$ & 0 \\
\hline $\mathrm{PRNr}$ & $20.7 \pm 6.5$ & $3.7 \pm 1.5$ & $10.0 \pm 7.9$ & $2.0 \pm 2.6$ \\
\hline contra SLD & & & $4.7 \pm 0.6$ & $1.3 \pm 1.5$ \\
\hline $\mathrm{KF}$ & $14.7 \pm 7.2$ & 0 & $6.3 \pm 4.9$ & $0.7 \pm 0.6$ \\
\hline PRNc & $73.7 \pm 24.5$ & $10.7 \pm 2.3$ & $29.3 \pm 28.4$ & $4.7 \pm 2.1$ \\
\hline $\mathrm{LC}$ & $2.7 \pm 0.6$ & 0 & 0 & 0 \\
\hline $\mathrm{RM}$ & $5.7 \pm 1.2$ & $3.0 \pm 0.0$ & 0 & 0 \\
\hline SPVO & $7.7 \pm 4.7$ & $0.3 \pm 0.6$ & $6.7 \pm 2.5$ & 0 \\
\hline PARNA & $3.7 \pm 1.5$ & $1.3 \pm 0.6$ & $3.7 \pm 4.0$ & 0 \\
\hline MV & $11.7 \pm 7.0$ & $1.3 \pm 0.6$ & $11.7 \pm 9.5$ & $1.0 \pm 1.0$ \\
\hline PGRNd & $6.3 \pm 5.1$ & $2.0 \pm 1.0$ & $11.7 \pm 9.2$ & $4.0 \pm 4.6$ \\
\hline GRN & $6.7 \pm 6.0$ & $1.3 \pm 1.5$ & $6.7 \pm 6.4$ & $2.0 \pm 1.0$ \\
\hline MARN & $6.0 \pm 3.6$ & $1.7 \pm 2.1$ & $2.0 \pm 1.0$ & $0.7 \pm 1.2$ \\
\hline PARN & $43.0 \pm 8.7$ & $7.7 \pm 1.2$ & $27.0 \pm 17.7$ & $4.0 \pm 1.0$ \\
\hline PGRNl & $20.7 \pm 11.6$ & $3.3 \pm 2.5$ & $8.0 \pm 3.0$ & $1.7 \pm 1.2$ \\
\hline NTS & $4.7 \pm 2.5$ & 0 & $1.3 \pm 2.3$ & $0.3 \pm 0.6$ \\
\hline
\end{tabular}

${ }^{\mathrm{a}}$ Numbers given correspond to the mean $\pm \mathrm{SD}$ of the average number of $\mathrm{CTb}$ singly and $\mathrm{CTb}$ and GAD double labeled cells counted on sections taken every $600 \mu \mathrm{m}$ in three animals per condition ipsilaterally and contralaterally in the principal afferents to the SLD. The relatively high SD is due to the fact that the number of retrogradely labeled neurons per structure was significantly inferior for all structures in one of the animals due to a slightly fainter $\mathrm{CTb}$ 
immunostaining. However, the distribution and the relative number per structure of the retrogradely labeled cells was similar in all three animals. Abbreviations: BST, bed nucleus of the stria terminalis; CEA, central nucleus of the amygdala; $\mathrm{dPAG}$, dorsal periaqueductal gray; $\mathrm{DR}$, dorsal raphe nucleus; GRN, gigantocellular reticular nucleus; IC, inferior colliculus; KF, Kölliker-Fuse subnucleus; LC, locus coeruleus; LDT, laterodorsal tegmental nucleus; LHA, lateral hypothalamic area; LPO, lateral preoptic area; MA, magnocellular preoptic nucleus; MARN, magnocellular reticular nucleus; MOp, primary motor area; MRN, mesencephalic reticular nucleus; MV, medial vestibular nucleus; NTS, nucleus of the solitary tract; PARN, parvicellular reticular nucleus; PARNA, parvicellular reticular nucleus alpha; PB1, lateral parabrachial nucleus; PGRNd, dorsal paragigantocellular reticular nucleus; PGRN1, lateral paragigantocellular reticular nucleus; $\mathrm{PH}$, posterior hypothalamus; PPN, pedonculopontine nucleus; PRNc, caudal pontine reticular nucleus; PRNr, rostral pontine reticular nucleus; PVH, paraventricular nucleus hypothalamus; RM, raphe magnus nucleus; rostPAG, rostral part of the periaqueductal gray; SC, superior colliculus; contra SLD, contralateral sublaterodorsal nucleus; $\mathrm{SNr}$, reticular substancia nigra; SPVO, oral part of the spinal nucleus of the trigeminal; SSs, supplemental somatosensory area; TM, tuberomammillary nucleus; vlPAG, ventrolateral periaqueductal gray; VTA, ventral tegmental area; ZI, zona incerta. 


\section{References}

Allen, G.V. \& Cechetto, D.F. (1992) Functional and anatomical organization of cardiovascular pressor and depressor sites in the lateral hypothalamic area: I. Descending projections. $J$. Comp. Neurol., 315, 313-332.

Bajic, D. \& Proudfit, H.K. (1999) Projections of neurons in the periaqueductal gray to pontine and medullary catecholamine cell groups involved in the modulation of nociception. J. Comp. Neurol., 405, 359-379.

Boissard, R., Gervasoni, D., Fort, P., Henninot, V., Barbagli, B. \& Luppi, P.H. (2000) Neuronal networks responsible for paradoxical sleep onset and maintenance in rats: a new hypothesis. Sleep, 23 Suppl, 107.

Boissard, R., Gervasoni, D., Schmidt, M.H., Barbagli, B., Fort, P. \& Luppi, P.H. (2002) The rat ponto-medullary network responsible for paradoxical sleep onset and maintenance: a combined microinjection and functional neuroanatomical study. Eur. J. Neurosci., In Press.

Cameron, A.A., Khan, I.A., Westlund, K.N. \& Willis, W.D. (1995) The efferent projections of the periaqueductal gray in the rat: a Phaseolus vulgaris-leucoagglutinin study. II. Descending projections. J. Comp. Neurol., 351, 585-601.

Deboer, T., Sanford, L.D., Ross, R.J. \& Morrison, A.R. (1998) Effects of electrical stimulation in the amygdala on ponto-geniculo-occipital waves in rats. Brain Res., 793, 305-310.

Ford, B., Holmes, C.J., Mainville, L. \& Jones, B.E. (1995) GABAergic neurons in the rat pontomesencephalic tegmentum: codistribution with cholinergic and other tegmental neurons projecting to the posterior lateral hypothalamus. J. Comp. Neurol., 363, 177-196.

George, R., Haslett, W.L. \& Jenden, D.J. (1964) A cholinergic mechanism in the brainstem reticular formation: induction of paradoxixal sleep. Int J Neuropharmacol, 3, 541-552.

Gervasoni, D., Darracq, L., Fort, P., Souliere, F., Chouvet, G. \& Luppi, P.H. (1998) Electrophysiological evidence that noradrenergic neurons of the rat locus coeruleus are tonically inhibited by GABA during sleep. Eur. J. Neurosci., 10, 964-970.

Gervasoni, D., Peyron, C., Rampon, C., Barbagli, B., Chouvet, G., Urbain, N., Fort, P. \& Luppi, P.H. (2000) Role and origin of the GABAergic innervation of dorsal raphe serotonergic neurons. J. Neurosci., 20, 4217-4225.

Graham, J. (1977) An autoradiographic study of the efferent connections of the superior colliculus in the cat. J. Comp. Neurol., 173, 629-654.

Graybiel, A.M. (1977) Direct and indirect preoculomotor pathways of the brainstem: an autoradiographic study of the pontine reticular formation in the cat. J. Comp. Neurol., 175, 37-78.

Holstege, G. (1987) Some anatomical observations on the projections from the hypothalamus to brainstem and spinal cord: an HRP and autoradiographic tracing study in the cat. J. Comp. Neurol., 260, 98-126.

Holstege, G., Meiners, L. \& Tan, K. (1985) Projections of the bed nucleus of the stria terminalis to the mesencephalon, pons, and medulla oblongata in the cat. Exp. Brain Res., 58, 379-391.

Hopkins, D.A. \& Holstege, G. (1978) Amygdaloid projections to the mesencephalon, pons and medulla oblongata in the cat. Exp. Brain Res., 32, 529-547.

Jones, B.E. \& Yang, T.Z. (1985) The efferent projections from the reticular formation and the locus coeruleus studied by anterograde and retrograde axonal transport in the rat. J. Comp. Neurol., 242, 56-92.

Krout, K.E., Jansen, A.S. \& Loewy, A.D. (1998) Periaqueductal gray matter projection to the parabrachial nucleus in rat. J. Comp. Neurol., 401, 437-454.

Lai, Y.Y., Clements, J.R. \& Siegel, J.M. (1993) Glutamatergic and cholinergic projections to the pontine inhibitory area identified with horseradish peroxidase retrograde transport and immunohistochemistry. J. Comp. Neurol., 336, 321-330. 
Lai, Y.Y. \& Siegel, J.M. (1991) Pontomedullary glutamate receptors mediating locomotion and muscle tone suppression. J. Neurosci., 11, 2931-2937.

Leichnetz, G.R., Carlton, S.M., Katayama, Y., Gonzalo-Ruiz, A., Holstege, G., DeSalles, A.A. \& Hayes, R.L. (1989) Afferent and efferent connections of the cholinoceptive medial pontine reticular formation (region of the ventral tegmental nucleus) in the cat. Brain Res. Bull., 22, 665-688.

Loewy, A.D., Wallach, J.H. \& McKellar, S. (1981) Efferent connections of the ventral medulla oblongata in the rat. Brain Res., 228, 63-80.

Luppi, P.H., Fort, P. \& Jouvet, M. (1990) Iontophoretic application of unconjugated cholera toxin B subunit $(\mathrm{CTb})$ combined with immunohistochemistry of neurochemical substances: a method for transmitter identification of retrogradely labeled neurons. Brain Res., 534, 209224.

Luppi, P.H., Gervasoni, D., Peyron, C., Barbagli, B., Boissard, R. \& Fort, P. (1999) Norepinephrine and REM Sleep. In Mallick, B.N., Inoue, S. (eds.) Rapid Eye Movement Sleep. Norosa Publishing Hoouse, New Delhi, pp. 107-122.

Maloney, K.J., Mainville, L. \& Jones, B.E. (2000) c-Fos expression in GABAergic, serotonergic, and other neurons of the pontomedullary reticular formation and raphe after paradoxical sleep deprivation and recovery. J. Neurosci., 20, 4669-4679.

Maquet, P., Peters, J., Aerts, J., Delfiore, G., Degueldre, C., Luxen, A. \& Franck, G. (1996) Functional neuroanatomy of human rapid-eye-movement sleep and dreaming. Nature, 383, 163-166.

McCarley, R.W., Ito, K. \& Rodrigo-Angulo, M.L. (1987) Physiological studies of brainstem reticular connectivity. II. Responses of mPRF neurons to stimulation of mesencephalic and contralateral pontine reticular formation. Brain Res., 409, 111-127.

Mitani, A., Ito, K., Hallanger, A.E., Wainer, B.H., Kataoka, K. \& McCarley, R.W. (1988) Cholinergic projections from the laterodorsal and pedunculopontine tegmental nuclei to the pontine gigantocellular tegmental field in the cat. Brain Res., 451, 397-402.

Moschovakis, A.K., Scudder, C.A. \& Highstein, S.M. (1996) The microscopic anatomy and physiology of the mammalian saccadic system. Prog. Neurobiol., 50, 133-254.

Onoe, H. \& Sakai, K. (1995) Kainate receptors: a novel mechanism in paradoxical (REM) sleep generation. Neuroreport, 6, 353-356.

Peyron, C., Luppi, P.H., Fort, P., Rampon, C. \& Jouvet, M. (1996) Lower brainstem catecholamine afferents to the rat dorsal raphe nucleus. J. Comp. Neurol., 364, 402-413.

Peyron, C., Petit, J.M., Rampon, C., Jouvet, M. \& Luppi, P.H. (1998a) Forebrain afferents to the rat dorsal raphe nucleus demonstrated by retrograde and anterograde tracing methods. Neuroscience, 82, 443-468.

Peyron, C., Tighe, D.K., van den Pol, A.N., de Lecea, L., Heller, H.C., Sutcliffe, J.G. \& Kilduff, T.S. (1998b) Neurons containing hypocretin (orexin) project to multiple neuronal systems. J. Neurosci., 18, 9996-10015.

Quattrochi, J.J., Mamelak, A.N., Madison, R.D., Macklis, J.D. \& Hobson, J.A. (1989) Mapping neuronal inputs to REM sleep induction sites with carbachol-fluorescent microspheres. Science, 245, 984-986.

Ricardo, J.A. (1981) Efferent connections of the subthalamic region in the rat. II. The zona incerta. Brain Res., 214, 43-60.

Robertson, R.T. \& Feiner, A.R. (1982) Diencephalic projections from the pontine reticular formation: autoradiographic studies in the cat. Brain Res., 239, 3-16.

Sakai, K., Sastre, J.P., Kanamori, N. \& Jouvet, M. (1981) State-specific neurones in the pontomedullary reticular formation with special reference to the postural atonia during paradoxical sleep in the cat. In Pompeiano, O., Aimone Marsan, C. (eds.) Brain Mechanisms of Perceptual Awareness and Purposeful Behavior. Raven Press, New York, pp. 405-429. 
Sastre, J.P., Buda, C., Kitahama, K. \& Jouvet, M. (1996) Importance of the ventrolateral region of the periaqueductal gray and adjacent tegmentum in the control of paradoxical sleep as studied by muscimol microinjections in the cat. Neuroscience, 74, 415-426.

Sastre, J.P., Buda, C., Lin, J.S. \& Jouvet, M. (2000) Differential c-fos expression in the rhinencephalon and striatum after enhanced sleep-wake states in the cat. Eur. J. Neurosci., 12, 1397-1410.

Semba, K. (1993) Aminergic and cholinergic afferents to REM sleep induction regions of the pontine reticular formation in the rat. J. Comp. Neurol., 330, 543-556.

Semba, K., Reiner, P.B. \& Fibiger, H.C. (1990) Single cholinergic mesopontine tegmental neurons project to both the pontine reticular formation and the thalamus in the rat. Neuroscience, 38, 643-654.

Shaikh, M.B., Barrett, J.A. \& Siegel, A. (1987) The pathways mediating affective defense and quiet biting attack behavior from the midbrain central gray of the cat: an autoradiographic study. Brain Res., 437, 9-25.

Shammah-Lagnado, S.J., Negrao, N., Silva, B.A. \& Ricardo, J.A. (1987) Afferent connections of the nuclei reticularis pontis oralis and caudalis: a horseradish peroxidase study in the rat. Neuroscience, 20, 961-989.

Sheibel, M.E. \& Sheibel, E.B. (1958) Structural substrates for integrative patterns in the brain stem reticular core. In Jasper, H.H., Proctor, L.D., Knighton, R.S., Noshay, W.C., Costello, R.T. (eds.) Reticular Formation of the Brain. Little, Brown§Co, Boston, pp. 31-68.

Shiromani, P.J., Armstrong, D.M. \& Gillin, J.C. (1988) Cholinergic neurons from the dorsolateral pons project to the medial pons: a WGA-HRP and choline acetyltransferase immunohistochemical study. Neurosci. Lett., 95, 19-23.

Siegel, J.M. (1979) Behavioral functions of the reticular formation. Brain Res., 180, 69-105.

Siegel, J.M. \& Tomaszewski, K.S. (1983) Behavioral organization of reticular formation: studies in the unrestrained cat. I. Cells related to axial, limb, eye, and other movements. $J$. Neurophysiol., 50, 696-716.

Van Bockstaele, E.J., Chan, J. \& Pickel, V.M. (1996) Input from central nucleus of the amygdala efferents to pericoerulear dendrites, some of which contain tyrosine hydroxylase immunoreactivity. J. Neurosci. Res., 45, 289-302.

Watanabe, K. \& Kawana, E. (1982) The cells of origin of the incertofugal projections to the tectum, thalamus, tegmentum and spinal cord in the rat: a study using the autoradiographic and horseradish peroxidase methods. Neuroscience, 7, 2389-2406.

Xi, M.C., Morales, F.R. \& Chase, M.H. (1999a) Evidence that wakefulness and REM sleep are controlled by a GABAergic pontine mechanism. J. Neurophysiol., 82, 2015-2019.

Xi, M.C., Morales, F.R. \& Chase, M.H. (1999b) A GABAergic pontine reticular system is involved in the control of wakefulness and sleep. Sleep Res Online, 2, 43-48.

Xi, M.C., Morales, F.R. \& Chase, M.H. (2001) The motor inhibitory system operating during active sleep is tonically suppressed by GABAergic mechanisms during other states. $J$. Neurophysiol., 86, 1908-1915.

Yasui, Y., Nakano, K., Nakagawa, Y., Kayahara, T., Shiroyama, T. \& Mizuno, N. (1992) Nondopaminergic neurons in the substantia nigra project to the reticular formation around the trigeminal motor nucleus in the rat. Brain Res., 585, 361-366. 